\title{
Needs Analysis of Japanese Engineers’ English Use Focusing on Technical Vocabulary
}

\author{
Yuka ISHIKAWA \\ Nagoya Institute of Technology \\ Nagoya, Japan \\ ishikawa.yuka@nitech.ac.jp
}

\begin{abstract}
In this paper, a vast amount of information about technical vocabulary use by working engineers is collected and analyzed to understand their English language needs. The aim of the research is to help develop an effective vocabulary learning system for university students majoring in engineering and technology as well as engineers who are currently working, based on the results of the survey. The questionnaires containing 80 question items were distributed online and 200 engineers responded to them. The results suggest that more than $50 \%$ of engineers use English at work every day or almost every day, and more than $80 \%$ agreed that technical vocabulary knowledge plays an important role in their work. More than $\mathbf{5 0 \%}$ said they need technical vocabulary knowledge during the course of a business meeting, and more than $20 \%$ said they learned technical vocabulary intentionally.
\end{abstract}

Keywords-ESP; engineering; needs analysis; technical vocabulary learning; questionnaires

\section{INTRODUCTION}

There is increasingly more attention paid to ESP, or English for specific purposes, in the field of English education at the university level as well as at the occupational or professional program level. ESP courses are primarily "designed to meet specified needs of the learner" and therefore usually focus on particular linguistic features, learning skills, discourses, and genres to be learned [1]. Several ESP teachers have conducted surveys on Japanese students' needs in order to improve the English curriculum or English teaching materials at their own college (e.g., [2])

Research surveys revealed that undergraduate and graduate students majoring in engineering and technology are often required to read and write academic papers in English in order to complete their academic tasks. Therefore, ESP courses began to be designed focusing on methods of reading and writing academic papers in English. Several ESP teaching materials including frequent linguistic patterns, ranging from lexicon to text structure, featuring academic papers were developed (e.g., [3])

"Needs," however, denotes a rather complicated phenomenon and is often an inclusive term as West (1994) pointed out [4]. For example, Hutchinson and Waters (1987) classified needs into three types: necessities, lacks, and wants. In addition, based on objective and subjective perspectives, they categorized "needs" into six types [5]. To conduct an accurate needs analysis, maximum possible information should be collected from various sources, including not only learners and teachers but also former students and workers already working in the target community [4]. It is important to clarify the needs of Japanese university graduates.

The purpose of this research is to conduct a thorough needs analysis from the perspective of a "needs analysis triangle" [4] and, based on the needs, develop the best possible ESP vocabulary learning system for Japanese university students majoring in engineering and related fields [6]. A detailed survey will present a clear picture of what they need to learn, to what extent, and how they need to learn. Of the three perspectives, this paper will survey the English language needs of Japanese workers who graduated from engineering departments or engineering-related departments of four-year colleges and universities, and who use English at work or in private life. In this paper, the word "engineer" is used in a broader sense, which refers to several types of graduates.

\section{LITERATURE REVIEW}

"Needs analysis" is generally conducted to improve an existing curriculum or to develop effective new courses in a particular educational institution. The primary task involves collecting information about the existing curriculum. For example, Koyama (2001) sent questionnaires about the present English language needs and English education they had at technical college to the alumni by mail. The results of the survey showed that $66 \%$ of 204 respondents use English at work, $11 \%$ of respondents use reading skills every day (most frequently of all the four language skills), and less than $2 \%$ use speaking or listening skills every day. Although very few admitted that pronunciation and knowledge of grammar knowledge are important at work (4\% and $3 \%$, respectively), nearly a quarter said that vocabulary is important at the workplace (28\%) [7].

Najar et al. (1998) sent similar questionnaires to the alumni of their school saying that the survey was conducted to improve English education at their old school. The results showed that about $40 \%$ of the 447 respondents said they use English at work. About 30\% said they spend more than half the time they use English for reading, and 9\% said they spend more than half the time they use English for listening, $8.5 \%$ for writing, and $7.5 \%$ for speaking. About $23 \%$ of respondents said that they read Internet documents in English, 22\% read 
equipment assembly or usage instructions, and $20 \%$ read professional journals [8].

The previous survey revealed Japanese engineers' language needs to some extent. Most Japanese engineers are required to read English. However, the survey did not clarify which aspects of vocabulary are required and to what extent by engineers who use English. As almost twenty years have passed since Koyama (2001) and Najar et al. (1998) conducted their surveys, a new survey is required to understand the status of engineers' language needs at present. Although the previous survey presented a rough idea, details about respondents' vocabulary knowledge or language-learning style were still untouched. In this study, a detailed questionnaire is used to survey the needs of engineers who use English at work.

\section{RESEARCH DESIGN}

\section{A. Aim and Research Questions}

This paper aims to explore Japanese workers' needs to use English at work, the language skill they need most (for example, reading or speaking), especially focusing on engineering technical vocabulary use, and investigate when and where and to what extent they use technical vocabulary to complete their tasks at their workplace. The survey also aims to clarify how they evaluate their own knowledge of technical English vocabulary, and how many technical words they think university students need to acquire before they begin work.

We distributed questionnaires to Japanese workers living in Japan about their need for using English at work based on the following five research questions:

\section{How often do they use English?}

2. For what purpose do they use English?

3. Why do they need technical vocabulary?

4. How many technical words should they know?

5. How do they learn technical vocabulary?

\section{B. Collecting Data}

Data were collected via the Internet by using a commercial survey system. The questionnaires comprise 80 items, divided into two parts. The first part includes a fixed set of questions seeking personal information such as age, sex, or marital status. A few other questions too are added to this section, by which this first part functions as a screening test. Respondents who said they are graduates of a four-year university majoring in engineering or related fields and who use English at work or in their private lives would move to take the second part of the survey; the rest would finish the questionnaire and leave the survey site. In the second part, the remaining respondents answer a variety of questions ranging from their experiences of working abroad, if they have, to their English proficiency and English language needs. Information about their learning motivation, attitudes, and learning strategies are also collected.

In this paper, we examine the responses of the 200 workers who completed both the first and the second part of the research questions mentioned earlier. The respondents are from different educational backgrounds, have different work experiences, and varying levels of English proficiency. They use English for different purposes and at different frequencies.

\section{Question items}

Apart from the screening part, some items helped us understand the characteristics of the respondents. Questions were also asked about the company they work for, their position in the company, the nature of the job they do, the engineering field related to their job, their study-abroad experience, their English proficiency level, and so on. From the questionnaire, the question items and their results discussed in this paper are shown in the appendix.

Some of the question items are focused on engineers' use of English at work, the purpose, and the frequency, which provides the answers to research questions 1 and 2. Identifying the skill they need most and the text genre they frequently come across leads us to the type of vocabulary knowledge they need most for using English at work: For example, if they often read specifications, they need visual receptive knowledge of words frequently used in specifications.

Questions also include asking respondents to evaluate their language skills, including vocabulary knowledge required to complete their job in English. Some other questions clarify when and in what situation they need vocabulary knowledge, and this leads us to answer research question 3.

To answer research question 4, we use respondents' reply to the question asking how many technical words university students need to know before starting their jobs. Some other questions also reveal aspects of technical word knowledge that engineers are required to know. They are given a word list and asked to pick up technical words they have come across at work. All these lead us to the answer to research question 4.

Questions about vocabulary learning strategies clarify how the respondents learned technical vocabulary and what they believed they should do to learn technical vocabulary. These lead us to the answer to research question 5.

\section{RESULTS AND DISCUSSION}

\section{A. Respondent Group}

The respondent group had 7 women and 93 men. Their ages ranged from 22 to 59, indicating that the set included workers who had just started their career as well as those who were nearing retirement. The average of their ages is around 40 . Thirty-five respondents are researchers and nine are teachers. One hundred and eight said they are engineers while twenty-six said they are salespersons. About half the number of respondents said they are working for a manufacturing company $(55.0 \%)$. Fifty-three percent have a bachelor's degree, while the rest have a master's degree $(38.5 \%)$ or a doctor's degree $(8.5 \%)$.

Questions about their degrees and their majors at university show that the primary major of the respondents is electrical and electronic engineering $(25.5 \%)$, followed by chemical engineering $(23.0 \%)$. Far less than half the number of respondents who are majors in chemical engineering $(39.1 \%)$, 
architecture (28.6\%), civil engineering (33.3\%), and physics $(35.7 \%)$ do not have master's degrees or doctor's degrees. Questions about their majors and their current work reveal that a certain portion of respondents majoring in chemical engineering $(32.6 \%)$ and physics $(35.7 \%)$ are working as researchers. About $20 \%$ of respondents with a bachelor's degree are working as salespersons $(19.9 \%)$ while $7.6 \%$ are working as researchers. About one fifth of the respondents with a master's degree and about three-quarters of those with a doctor's degree are working as researchers.

About half the number of respondents answered they have some experience working in foreign countries $(n=99)$, and $14.5 \%$ said they have worked abroad for more than one year. On the other hand, $4.5 \%$ said that they have worked abroad for just a few days, and another $7.5 \%$ said they have worked abroad for a period between one week and one month. The work experience in foreign countries may influence their language learning motivation or their way of thinking about language learning. Their TOEIC (Test of English for International Communication) scores varied widely, and $6 \%$ said their score was under 400 while $4.5 \%$ said their score was over 900 . The largest group accounted for $19.5 \%$, whose score fell between 600 and 695 .

\section{B. Research Question 1. How often do they use English?}

More than half the number of respondents answered that they use technical English at work almost every day (31.5\%) or more than three days a week (23.0\%). Together with another $22.0 \%$ who said they use technical English at least once a week, almost $80 \%$ use technical English at work. They also said that they use technical English (77.0\%) more than general English $(60.0 \%)$ at work.

\section{Research Question 2. For what purpose do they use English?}

Several questions related to their English use are expected to clarify the purpose for which they use English. The first three questions in this section ask about the 1) frequency of speaking and listening to English, 2) frequency of reading English, and 3) frequency of writing English.

The results show that about one-third the number of respondents read English almost every day (19.0\%) or more than three days a week (14.5\%), while $27.0 \%$ write English almost every day $(14.5 \%)$ and more than three days a week $(12.5 \%)$. Compared to these figures, the rate of respondents who listen to and speak English almost every day $(12.5 \%)$ and more than three days a week (8.5\%) is relatively lower (21.0\%). Engineers use their reading skills most at work.

A more minute survey shows that $43.5 \%$ respondents listen to and speak English at business meetings, 37.5\% use English in business negotiations, $38.0 \%$ use English on the telephone, and $27.5 \%$ use English for making presentations. When they write English, 15-25\% use technical English in writing specifications $(25.5 \%)$, reports $(25.5 \%)$, academic papers $(19.5 \%)$, planning papers $(18.5 \%)$, and manuals $(15.5 \%)$, in addition to writing e-mail in English (69.5\%) and English business letters (34.0\%). When they read English, 30-50\% said they read technical English such as specifications (45.5\%), academic papers $(35.0 \%)$, manuals $(33.5 \%)$, reports $(29.0 \%)$, catalogues $(21.0 \%)$, planning papers $(19.5 \%)$ in addition to English e-mail (75.0\%) and business letters (39.5\%). Japanese workers need to use technical English at work together with business English.

\section{Research Question 3. Why do they need technical vocabulary knowledge?}

Most respondents $(82.0 \%)$ agreed that technical vocabulary knowledge is very important $(29.5 \%)$ or important $(52.2 \%)$ to complete their job.

When do they need technical vocabulary knowledge? More than $50 \%$ of the number of respondents said they needed technical vocabulary knowledge while they were in a business meeting $(54.5 \%)$, about $50 \%$ said they need it while making presentations $(50.5 \%)$ and reading $(50.0 \%)$, and about $30 \%$ need the knowledge while in a business negotiation $(33.0 \%)$. The survey revealed that Japanese workers use technical vocabulary in a business meeting and business negotiation, which had seemed to require them to use business vocabulary.

When we limit our discussion to the respondents who read English almost every day, about 95\% think technical English vocabulary is very important $(52.6 \%)$ or important $(42.1 \%)$. All respondents who read English more than three days a week think technical vocabulary is very important $(34.5 \%)$ or important (65.5\%). Engineers who read English at work tend to consider technical vocabulary knowledge as important.

\section{E. Research Question 4. How many technical words should they know?}

It is said that Japanese university students have acquired 3,000 or 4,000 English words by the time of graduation. Is this vocabulary size appropriate and sufficient to accomplish their jobs? If not, how many technical words should engineers know? The first question in this section asks how many technical words engineers think they need to know in addition to the 3,000 or 4,000 English words. The question does not mention whether the presumed 3,000 or 4,000 words are technical vocabulary or general vocabulary. About $30 \%$ of the respondents said that, in addition to the vocabulary acquired at university, they need to know at least an additional 2,000 technical English words (15.0\%) or an additional 3,000 technical English words (16.5\%) after gaining employment.

One of the questions asks engineers to read a given word list and pick up words they have come across at work. The list has 20 technical words selected from a word list based on an engineering corpus, EVE 9000, or English Vocabulary for Engineering 9000 [6]. The most frequent word in the word list is "density" and $72 \%$ of the respondents said they have encountered the word at work. This percentage is the highest. Almost $10 \%$ of the respondents said they have not come across any of the listed words at work. Apart from this $10 \%$, the smallest group is the one that has come across the word "biphasic" $(21.0 \%)$, whose frequency is actually low (less than 5 pmw in the corpus) and it is in the most infrequent group in the word list. The results suggest that about $20 \%$ of respondents admitted they need to know 9,000 technical words in the EVE word list, including the most infrequent group. 
To identify how well Japanese engineers need to know technical vocabulary, questions about each aspect of word knowledge such as pronunciation or spelling are asked. With regard to the receptive knowledge of a word, which makes us understand its meaning when we see or hear the word, nearly $70 \%$ of the engineers think it is very important or important to have receptive knowledge. This is the biggest group. Twentythree percent said visual word recognition is very important, and $47.5 \%$ said it is important. Twenty-four percent said aural word recognition is very important, and $45.0 \%$ said it is important.

The second group chose knowledge of translation and collocation. Over $60 \%$ of engineers believe this knowledge is very important or important. Knowledge of translation refers to the recollection of an appropriate English word for a Japanese technical word, and this ability is regarded as very important by $20.0 \%$ of the respondents, and considered as important by $44.0 \%$. Knowledge of word collocation is evaluated relatively highly (very important by $17.5 \%$, and important by $45.5 \%$ ).

Oral productive knowledge, which enables us to pronounce a word, spelling knowledge, which enables us to spell the word correctly, and more minute knowledge of the word such as its derivations, synonyms, or antonyms is given a lesser evaluation than other aspects of knowledge.

\section{F. Research Question 5. How do they learn technical vocabulary?}

Most of respondents said they acquired technical vocabulary "naturally" in the course of doing their job (78.0\%); however, $10.5 \%$ of them went to an English study school to learn technical vocabulary, and $10.5 \%$ made efforts to study technical words intentionally by themselves. It is clear that more than $20 \%$ of the engineers need intentional technical vocabulary learning.

When asked how the respondents tackled unknown words that they came across during work, $87 \%$ said they used a dictionary (online dictionary $74 \%$, and regular paper dictionary $14 \%) ; 7.5 \%$ said they would try to understand the meaning by analogy and did not look it up in dictionaries; and 5.5\% said they just asked colleagues for the meaning. The analogy group contains 15 engineers, and 14 out of 15 said they use English almost every day or at least once a week. Only one among the 15 used English only once a month.

The results suggest that engineers need to expand their technical vocabulary knowledge, and most of them have learned technical vocabulary after graduation. Although engineers said they picked up technical vocabulary "naturally" in the course of their work, most of them use dictionaries for learning the meaning of words. Besides learning vocabulary at English school, some of them make word lists by themselves, and most of them have acquired some technical vocabulary.

Some questions in the questionnaire ask them to state an effective way to learn technical words. The largest group believe that reading or listening English a lot is effective to learn technical vocabulary $(22.5 \%$ said very effective and $39.0 \%$ said effective). This is followed by the group who believe that saying the word aloud is very effective (18.5\%), or effective (38.0\%). In the smallest group, $8.5 \%$ believe that the keyword mnemonic method or using puns is very effective, and $20.5 \%$ believe this method to be effective.

\section{CONCLUSION}

Although a fair amount of ESP vocabulary-learning materials have been developed, very few needs analyses on ESP vocabulary have been conducted so far. This study aims to clarify the English vocabulary needs of Japanese engineers: the kind of vocabulary they need to have and to what extent. To collect data, we distributed a questionnaire of 80 items to 200 engineers. The results of the survey indicated that more than half the number of respondents use English at work every day or more than 3 days a week. More than $80 \%$ agreed that technical vocabulary knowledge is important at work. They need technical vocabulary knowledge while they are at business meetings, presentations, or business negotiations as well as reading papers. The results suggest they need knowledge about the pronunciation aspects of the words as well. Moreover, the survey clarified that about $20 \%$ have come across words in the least frequent group of EVE 9000 word list in the course of their work. That can lead us to the conclusion that teaching technical vocabulary using the EVE 9,000 word list may be effective for all types of engineers.

\section{ACKNOWLEDGMENT}

This work was supported by JSPS KAKENHI Grant Number 16H03445.

\section{REFERENCES}

[1] T. Dudley-Evans, and M. J. St John, Developments in English for Specific Purposes, Cambridge, UK: Cambridge University Press, 1998, pp. 4-5.

[2] S. Yokoyama, "Research on effective syllabus design and materials development for teaching ESP at the tertiary level," 2005, unpublished report. Retrieved from http://kojimakei.jp/english/scientific /scientific2005.pdf

[3] Y. Ishikawa, "Bridging the gap between general English and academic English," in Weir, G., Ishikawa, S., and Poonpon, K. (Eds.) Corpora and language technologies in teaching, learning and research, Glasgow, UK: University of Strathclyde Publishing, 2011, pp. 87-94.

[4] R. West, "Needs analysis in language teaching," in Language Teaching, Cambridge University Press, 1994, pp. 1-19.

[5] T. Hutchinson, and A Waters, English for Specific Purposes: A Learning-Centred Approach, 1987, Cambridge, UK: Cambridge University Press, 1987, pp. 53-63.

[6] Y. Ishikawa, "Development of English Vocabulary for Engineers 9000," 2017, The Institute of Statistical Mathematics Research Collaboration Reports, 373-374, pp. 129-148.

[7] Y. Koyama, "Kogakukei Daigaku ni okeru eigokyouiku no genjokaiseki to kourituteki sisutemu no koutiku [Based on survey on the present situation and constructing an effective English education system at engineering faculty]," 2001, unpublished.

[8] R. Najar, G. Kellogg, L. S. Rogstad, L. Sakka, and J. Thurman, "A needs analysis of the English language requirements of KIT courses and the workplace," 1998, unpublished.

\section{APPENDIX}

The main items of the questionnaire used for this study are translated below with multiple-choice answers. The original 
survey was conducted in Japanese. The numbers in parentheses represent the numbers of respondents who chose a particular option.

\section{Q1. Sex: Male (193), Female (7) \\ Q2. Age: (average: 40.6)}

Q9. The highest level of schooling you have completed: Junior high school, Senior high school, 2-year university, 4year university, or graduate school (200)

Q11. The most related field to engineering you studied at (graduate) university: Language/literature, Law/politics, Economics/ business (4), Arts, Physical education, Medicine/nursing/health care, Science/engineering/information (196), Others

Q12. Do you use specific knowledge related to engineering in your everyday work? Yes (112), Yes, to some extent (62), Yes, but not much (22), No, rarely (0), Not clear (4)

Q13-Q14. To what extent do you use (A) technical English $/(B)$ general English in everyday work? Almost every day (A: 63, B: 48), More than 3 days a week (A: 46, B: 42), About once a week (A: 45, B: 30), About once a month (A: 24 , B: 23), About once in 2-3 months (A: 19, B: 20), About once a year (A: 1, B: 4), Rarely (A: 2, B: 33)

Q15-Q16. To what extent do you use (A) technical English/(B) general English in private life? Almost every day (A: 26, B: 22), More than 3 days a week (A: 23, B: 20), About once a week (A: 28, B: 32), About once a month (A: 21, B: 27), About once in 2-3 months (A: 12, B: 16), About once a year (A: 5, B: 11), Rarely (A: 85, B: 72)

Q17. Classify the industry type of the company you work for: Construction (10), Manufacture, food (2), Manufacture, textile (1), Manufacture, printing (1), Manufacture, iron, steel, non-ferrous metals, and chemicals (13), Manufacture, general machinery (9), Manufacture, electrical machinery (32), Manufacture, transportation equipment (19), Manufacture, precision machinery (5), Manufacture, others (28), Electricity, gas, water (2), Transportation, information and communication (3), Wholesale trade/retail trade (9), Service (33), National public servant (5), Local public servant (7), Public cooperation (2), University faculty member (3), Technical college faculty member (1), High school teacher (3), Teacher of any other type of school (1), Others (11)

Q19. What is your line of work? Research (35), Education (9), Technician (108), Clerk (13), Sales and service (26), Floor work or field work (4), Executive (5)

$Q 20$.

Position:

Executive/manager

(15),

Director/department head (23), Section chief/section head (46), Full time staff (110), Part-time staff (6)

Q21. University type you graduated: National (111), Prefectural (14), Private (73), Overseas (2)

Q24. The highest degree you have: Bachelor's (106), Master's (64), Master's + Doctoral course (13), Doctor's (17)

Q25. The academic field most related to your major at (graduate) school: chemical engineering (46), mechanical engineering (37), material engineering (4), computer science (35), electrical \& electronic engineering (51), civil engineering (6), physics (14), architecture (7)

Q26. The academic field most related to the job you are doing: chemical engineering (41), mechanical engineering (38), material engineering (6), computer science (37), electrical \& electronic engineering (57), civil engineering (6), physics (6), architecture (9)

Q29. The duration for which you worked abroad in English-speaking countries: More than 1 year (29), More than 6 months (18), More than 1 month (28), More than 1 week (15), Few days (9), None (101)

Q30. The duration for which you worked abroad in nonEnglish-speaking countries: More than 1 year (29), More than 6 months (22), More than 1 month (22), More than 1 week (12), Few days (12), None (103)

Q31. Your TOEIC score: Less than 400 (12), 400-495 (13), 500-595 (23), 600-695 (39), 700-795 (32), 800-895 (19), 900990 (9), No score (91)

Q32. In what context do you listen to or speak English at work? Business negotiation (75), Meeting (face-to face) (87), Meeting (video) (70), Telephone conversation (76), Party (41), Presentation (55), Others (1), Not specified (64)

Q34. In what context do you read English at work? e-mail (150), Business letters (79), FAX (32), Specifications (91), Academic papers (70), Technical manuals (67), Advertisements (22), Catalogs (42), Planning papers (39), Reports (58), Others (2), Not specified (22)

Q36. In what situation do you write English at work? email (139), Business letters (68), FAX (27), Specifications (51) Academic papers (39), Technical manuals (31), Advertisements (13), Catalogs (20), Planning papers (37), Reports (51), Others (2), Not specified (42)

Q38. How often do you use English speaking or listening skills at work (such as in business meetings, telephone conversations, presentations)? Almost every day (25), More than 3 days a week (17), About once a week (29), About once a month (25), About once in 2-3 months (24), About once a year (8), Rarely (72)

Q39. How often do you read English at work (such as papers, e-mail, technical manuals)? Almost every day (38), More than 3 days a week (29), About once a week (38), About once a month (28), About once in 2-3 months (14), About once a year (8), Rarely (45)

Q40. How often do you write English at work (such as in papers, e-mail, technical manuals)? Almost every day (29), More than 3 days a week (25), About once a week (32), About once a month (25), About once in 2-3 months (15), About once a year (13), Rarely (61)

Q42-Q46. To complete a task in English, your (A) reading ability $/(B)$ listening ability $/(C)$ writing ability/(D) speaking ability/(E) vocabulary knowledge is: Sufficient (A: 26, B: 18, C: 17, D: 18, E: 19), Somewhat sufficient (A: 46, B: 33, C: 35, D: 29, E: 29), Don't know (A: 39, B: 47, C: 46, D: 36, E: 47), 
Somewhat insufficient (A: 38, B: 40, C: 40, D: 44, E:43), Insufficient (A: 51, B: 62, C: 62, D: 73, E: 62)

Q49. Japanese university students are known to acquire 3,000 or 4,000 English words by graduation. Judging from your experience, how many technical words should they learn in addition to this? None (22), 1,000 (18), 2,000 (30), 3,000 (33), 4,000 (15), 5,000 (13), 6,000 (5), More than 7,000 (16), Don't know (48)

Q50. How did you learn technical vocabulary? At work (155), At English school (21), Using word lists (21) Others (3)

Q52. Do you think using a word list is effective to learn technical vocabulary? Very effective (25), Effective (50), Don't know (61), Not really effective (35), Almost ineffective (29)

Q53. Do you think reading dictionary description/examples is effective to learn technical vocabulary? Very effective (31), Effective (73), Don't know (61), Not really effective (18), Almost ineffective (17)

Q54. Do you believe that making sentences in English is effective to learn technical vocabulary? Very effective (36), Effective (67), Don't know (73), Not really effective (9), Almost ineffective (15)

Q55. Do you believe that testing your technical vocabulary knowledge periodically is effective? Very effective (34), Effective (62), Don't know (68), Not really effective (23), Almost ineffective (13)

Q56. Do you believe that reading a lot of English or listening to it is effective to learn technical vocabulary? Very effective (25), Effective (50), Don't know (61), Not really effective (35), Almost ineffective (29)

Q57. Do you believe that reading aloud repeatedly is effective to learn technical vocabulary? Very effective (37), Effective (76), Don't know (63), Not really effective (18), Almost ineffective (6)

Q58. Do you believe that writing English repeatedly is effective to learn technical vocabulary? Very effective (31), Effective (73), Don't know (70), Not really effective (13), Almost ineffective (13)

Q59. Do you think the keyword method (mnemonics) is effective to learn technical vocabulary? Very effective (17), Effective (41), Don't know (84), Not really effective (34), Almost ineffective (24)

Q60. Do you think that grouping synonyms or antonyms is effective to learn technical vocabulary? Very effective (23), Effective (69), Don't know (71), Not really effective (21), Almost ineffective (16)

Q61. Do you think grouping derivatives is effective to learn technical vocabulary? Very effective (23), Effective (61), Don't know (80), Not really effective (21), Almost ineffective (15)

Q62. Do you think learning vocabulary with colleagues is effective? Very effective (24), Effective (55), Don't know (73), Not really effective (27), Almost ineffective (21)
Q63. Do you think knowledge of technical vocabulary is important when you work in the engineering field? Very important (59), Important (105), Neutral (25), low importance (6), not at all (5)

Q64. In what situation do you need knowledge of technical vocabulary? Business meetings (109), Presentations (101), Reading (100), Business negotiations (66), Writing (52), Others (2)

Q66. What do you usually do when you come across unknown words in everyday work? Use online dictionary (148), Paper dictionary (26), Ask colleagues (11), Use an analogy to get a rough idea of the meaning and not use a dictionary (15)

Q68. How important is the ability to understand the meaning of a technical word you come across? Very important (46), Important (95), Don't know (46), Not really important (10), Not at all (3)

Q69. How important is the ability to understand the meaning of a technical word when you hear it being spoken? Very important (48), Important (90), Don't know (48), Not really important (10), Not at all (4)

Q70. How important is the ability to pronounce a technical word correctly? Very important (39), Important (77), Don't know (60), Not really important (17), Not at all (7)

Q71. How important is the ability to spell a technical word correctly? Very important (34), Important (78), Don't know (65), Not really important (17), Not at all (6)

Q72. How important is the ability to remember related words (plural forms, derivatives, synonyms, or antonyms) when you come across a technical word? Very important (29), Important (78), Don't know (68), Not really important (15), Not at all (10)

Q73. How important is the ability to remember related words (frequent collocations or phrases)? Very important (35), Important (91), Don't know (58), Not really important (10), Not at all (6)

Q74. How important is the ability to remember the corresponding English technical words (translation)? Very important (40), Important (88), Don't know (60), Not really important (6), Not at all (6)

Q76. Pick up the words that you have come across at work. density (145), vessel (105), gene (87), differentiable (97), fission (46), orthogonal (71), polygon (126), polysaccharide (59), supersaturation (73), dehydrate (66), cryogenic (57), substrate (97), oscillation (82), laminate (85), innovation (131), integration (116), regulator (122), electrolysis (91), convergence (92), magnetite (84), catabolism (54), biphasic (42), entropy (114), eigenvalue (48), conservation (98), not come across any of them (20) 